\title{
Research on production simulation method of integrated energy system
}

\author{
Guanghui Hua ${ }^{1}$, Xiaohui Xu${ }^{1}$, Yong Zhang ${ }^{2}$, Tao $\mathrm{Shi}^{3}$ \\ ${ }^{1}$ China Electric Power Research Institute, 210003 Nanjing, China \\ ${ }^{2}$ State Grid Hebei Electric Power Co., Ltd, 050021, Shijiazhuang, China \\ ${ }^{3}$ Nanjing University of Posts and Telecommunications, 210023 Nanjing, China
}

\begin{abstract}
In this paper, a production simulation method of regional integrated energy system considering the randomness of the scene is proposed to solve the production decision problem of integrated energy system including wind power, photovoltaic and other intermittent renewable energy sources. This method firstly establishes the typical scenario set of the integrated energy system operation with the corresponding random probability through cluster analysis. Secondly, taking the regional integrated energy system as the object, a production decision model and algorithm with the goal of minimizing the expected energy consumption cost are proposed. Finally, the effectiveness of the model algorithm is verified by a case study.
\end{abstract}

\section{Introduction}

As an important tool for power planning, operation scheduling and reliability analysis, production simulation has been widely studied and applied. The traditional production simulation is mainly to optimize the production situation of the generator set, consider the random failure of the generator set and the randomness of the load, so as to calculate the target value of generating capacity, system production cost and reliability index of each generator set under the corresponding operation mode. In terms of algorithm research, since the early 1970 $\mathrm{s}$ Booth put forward since the stochastic production simulation algorithm based on convolution operation, after more than 40 years of research, the domestic and foreign scholars have put forward the direct convolution method, flourier series method, the piecewise linear method, the cumulant method (semi invariants method), equivalent power method of classical analytic algorithm is proposed [1-2]. The core of this algorithm is to transform the sequential load curve into the continuous load curve. The effect of the random shutdown of each generator set on the continuous load curve is shown as the continuous load increases, forming the equivalent load continuous curve. The above algorithm generally adopts the continuous load curve and ignores the timing characteristics of the load, so it is difficult to deal with the problem of stochastic production simulation of timedependent power supplies. Later scholars put forward a series of stochastic production simulation algorithms for power system considering time series characteristics [34].

In recent years, with the maturity and development of intermittent renewable energy power generation technologies such as wind power and photovoltaics and the construction of an integrated energy system characterized by "multiple energy complementarity and coordinated operation", The production simulation of an integrated energy system with a high proportion of intermittent renewable energy has also become the focus of researchers [5-6]. Aiming at the above problems, based on stochastic programming theory, this paper establishes a random production simulation expected value model with the goal of minimizing the energy consumption cost of the regional integrated energy system, proposes the algorithm steps using scene clustering and genetic algorithm, and analyses. Through typical cases, the feasibility and effectiveness of this method are verified.

\section{Typical production scenarios for integrated energy systems}

According to the scale of energy supply and geographical distribution, the integrated energy system can be divided into user-type integrated energy system, regional integrated energy system and cross-region integrated energy system. Among them, regional integrated energy system is the main form of integrated energy system, which aims to meet the energy demand of cold/heat, electricity and gas in a certain region. It is formed by the coupling connection of intelligent power distribution system, medium and low pressure gas supply system and regional thermal system. The operation scenario of the integrated energy system is influenced by the natural resource conditions and user demand, and the output and load power of renewable energy generation represented by wind power and photovoltaic power generation show a certain randomness. Suppose there are $\mathrm{m}$ random sources in the system, and the active power of the random source $\mathrm{j}$ at time $\mathrm{t}$ (outflow is positive, inflow is negative)

\footnotetext{
* Corresponding author: Tao Shi ,haiou8081@163.com
} 
is $P_{i j}$, then in the time period $\mathrm{T}$, the system "random source" time-series scene can be expressed as :

$$
\begin{gathered}
\mathrm{S}=\left[\begin{array}{ccccc}
P_{11} & \cdots & P_{1 \mathrm{j}} & \cdots & P_{1 \mathrm{~m}} \\
\vdots & \ddots & \vdots & \ddots & \vdots \\
P_{\mathrm{i} 1} & \cdots & P_{\mathrm{ij}} & \cdots & P_{\mathrm{im}} \\
\vdots & \ddots & \vdots & \ddots & \vdots \\
P_{\mathrm{n} 1} & \cdots & P_{\mathrm{nj}} & \cdots & P_{\mathrm{nm}}
\end{array}\right] \\
i=1,2, \cdots n, \quad j=1,2, \cdots m
\end{gathered}
$$

Where: is a sequence scene matrix of random source; Time periods are divided into time periods, Unit time $\Delta t=T / n$.

Set the sample number of random source timing sequence scene as, then the typical scene set of the regional integrated energy system is $\left\{S_{k}\right\}, k=1,2, \cdots, K$. Considering the similarity and difference between the time sequence scene samples, the clustering algorithm (C4.5, k-means, Support Vector Machines algorithm, etc.) was used to obtain the typical regional integrated energy system configuration scenarios, $K^{\prime}<K$. For the typical scenario of category $d$, the sample mean of the same type of scenario is used as the quantitative description of this type of scenario, that is:

$$
\begin{gathered}
S_{d}^{\prime}=\frac{\sum_{k \in d} S_{k}}{k_{d}}, d=1,2, \cdots, K^{\prime} \\
q_{d}=\frac{k_{d}}{K}, d=1,2, \cdots, K^{\prime}
\end{gathered}
$$

Where: $S_{d}^{\prime}$ is the typical scene matrix of class $d ; k_{d}$ is the number of samples included in the typical scenario of category $d ; q_{d}$ is the corresponding distribution probability of the typical scenario of class $d$ in the sample space.

\section{Production simulation models and algorithms}

\subsection{Objective function}

In this paper, with the goal of minimizing the comprehensive Energy consumption cost of the Regional Integrated Energy System within the production simulation cycle, RIES random production simulation model is established, and its objective function is shown in equation (4).

$$
\min f=E\left[\sum_{t=1}^{n}\left(\sum_{i=1}^{n_{e}} c_{i} \cdot p_{i t}+\sum_{j=1}^{n_{h}} c_{j} \cdot q_{j t}+\sum_{k=1}^{n_{c}} C_{k t}-C_{e x}\right) \cdot \Delta t\right]
$$

Where:

$$
\begin{aligned}
& C_{k t}=c_{k p} \cdot p_{k t}+c_{k q} \cdot q_{k t} \\
& C_{e x}= \begin{cases}c_{g t} \cdot P_{x t} & P_{x t}<0 \\
c_{s t} \cdot P_{x t} & P_{x t} \geq 0\end{cases}
\end{aligned}
$$

Where, $\mathrm{E}$ is the expected value operator; $\mathrm{n}$ is the total number of time periods corresponding to the scheduling period; $\Delta t$ is the length of unit time; $n_{e}$ is the number of power sources; $n_{h}$ is the number of heat sources; $n_{c}$ is the number of cogeneration units; $c_{i}$ is the unit generation cost of the power source $i$; $c_{j}$ is the unit heating cost of the heat source $\mathrm{j} ; c_{k p}$ is the unit power generation cost of the cogeneration unit $\mathrm{k} ; c_{k q}$ is the unit heating cost of the cogeneration unit $\mathrm{k} ; c_{g t}$ is the unit price of electric quantity purchased online by RIES in the period $\mathrm{t} ; c_{s t}$ is the unit price of grid electricity of RIES in the period t; $p_{i t}$ is the power generated by the power source $i$ at the time period $\mathrm{t} ; q_{j t}$ is the heating power of the heat source $\mathrm{j}$ at the time period $\mathrm{t} ; p_{k t}$ is the generating capacity of the cogeneration unit $\mathrm{k}$ in the time period $\mathrm{t} ; q_{k t}$ is the heating quantity of the cogeneration unit $\mathrm{k}$ at the time period $\mathrm{t} ; P_{x t}$ is the power injected by RIES into the external public grid at time $\mathrm{t}$.

\subsection{Constraint condition}

During RIES operation, power balance, thermal balance, unit output upper and lower limits, charge and discharge capacity, heat storage capacity and other constraints should be satisfied [7-8].

\subsubsection{Power balance constraint}

$$
P_{L t}+P_{\text {losst }}+P_{x t}=\sum_{i=1}^{n_{e}} p_{i t}+\sum_{k=1}^{n_{c}} p_{k t}+P_{s t}
$$

Where, $P_{L t}$ is the power load demand at the time period $\mathrm{t}$; $P_{\text {losst }}$ is the power loss of the power network at time period $\mathrm{t}$; $P_{s t}$ is the charging and discharging power of the electric energy storage facility in the period $t$ (discharge is positive, charge is negative).

\subsubsection{Thermodynamic equilibrium constraint}

$$
Q_{L t}+Q_{\text {losst }}=\sum_{i=1}^{n_{h}} q_{i t}+\sum_{k=1}^{n_{c}} q_{k t}+Q_{s t}
$$

Where: $Q_{L t}$ is the thermal load demand at time period t; $Q_{\text {losst }}$ is the thermal network loss power at time period t; $Q_{s t}$ is the heat absorption and release power of the heat storage facility in the period $t$ (positive heat release and negative heat absorption).

\subsubsection{Power supply output constraint}

$$
p_{i \min } \leq p_{i} \leq p_{i \max }
$$

Where: $p_{i}$ is the output of the power supply $\mathrm{i}$; $p_{\text {imax }}, p_{\text {imin }}$ are the upper limits of the power output $i$ respectively.

\subsubsection{Heat source output constraint}

$$
q_{j \min } \leq q_{j t} \leq q_{j \max }
$$


Where: $q_{j}$ is the output of the heat source $\mathrm{j}$ at the time period $\mathrm{t} ; q_{\text {jmax }}, q_{\text {jmin }}$ are the upper and lower limits of the reservoir output $\mathrm{j}$ respectively.

\subsubsection{Thermoelectric coupling operating constraint}

$$
\begin{aligned}
& p_{k \text { min }}\left(q_{k}\right) \leq p_{k t} \leq p_{k \text { max }}\left(q_{k}\right) \\
& q_{k \text { min }}\left(p_{k}\right) \leq q_{k t} \leq q_{k \text { max }}\left(p_{k}\right)
\end{aligned}
$$

In the above formula: $p_{k t}$ is the generating output of the cogeneration unit $\mathrm{k}$ in time period $\mathrm{t} ; p_{\text {kmax }}\left(q_{k}\right)$, $p_{k \min }\left(q_{k}\right)$ is the upper and lower limits of the generating output of the cogeneration unit $\mathrm{k} ; q_{k t}$ is the heating output of cogeneration units $\mathrm{k}$ in time period $\mathrm{t} ; q_{k \max }\left(p_{k}\right)$, $q_{\text {knin }}\left(p_{k}\right)$ are the upper and lower limits of the heating output of the cogeneration unit $\mathrm{k}$.

\subsubsection{Battery storage facility charge/discharge constraint}

$$
\begin{gathered}
P_{s \min } \leq\left|P_{s t}\right| \leq P_{s \max } \\
E S_{e \text { min }} \leq E S_{e t} \leq E S_{e \max }
\end{gathered}
$$

Where: $P_{s t}$ is the charging/discharging power of the battery energy storage facility in time period t; $P_{\text {smax }}, P_{\text {smin }}$ are the upper and lower limits of charging/discharging power of battery storage facilities; $E S_{e t}$ is the energy state of the battery storage facility in time period t; $E S_{\text {emax }}, E S_{\text {emin }}$ are the upper and lower limits of the energy storage space of battery energy storage facilities.

\subsubsection{Heat storage facility suction/discharge} restraint

$$
\begin{gathered}
Q_{s \text { min }} \leq\left|Q_{s t}\right| \leq Q_{s \max } \\
E S_{h \text { min }} \leq E S_{h t} \leq E S_{h \text { max }}
\end{gathered}
$$

Where: $Q_{s t}$ is the heat absorbing/exothermic power of the heat storage facility in time period $\mathrm{t} ; Q_{\text {smax }}, Q_{\text {smin }}$ are upper and lower limits of heat absorption/emission power of heat storage facilities; $E S_{h t}$ is the energy state of the heat storage facility in time period t; $E S_{\text {hmax }}, E S_{\text {hmin }}$ are the upper and lower limits of the energy storage space of the heat storage facility.

\subsubsection{Tie line power constraint}

$$
0 \leq\left|P_{x t}\right| \leq P_{x \max }
$$

Where, $P_{x \max }$ is the limit value of the switching power of the tie line.

\subsection{Algorithm flow}

The method firstly establishes the typical scene set of regional integrated energy system through scene clustering. Secondly, based on the production decision model, the production plan of each typical scenario is obtained one by one. Finally, the expected value of the production decision scheme is obtained based on the random distribution probability of each typical scenario.

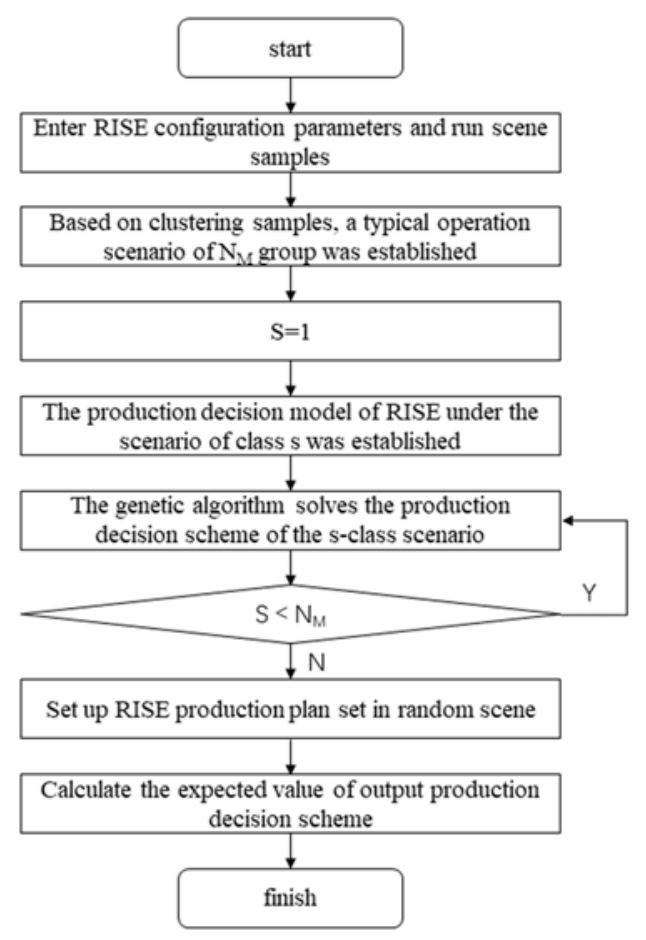

Fig 1. Production simulation process

\section{Case study}

A regional integrated energy system includes $20 \mathrm{MW}$ photovoltaic power generation and $20 \mathrm{MW}$ wind power generation. Energy storage battery $2 \mathrm{MW} / 2 \mathrm{MWh}$; Regenerative electric boiler 2MW/2MWh; Gas turbine cogeneration system is $5 \mathrm{MW}$, generating efficiency is $27.1 \%$, electric heating ratio is 0.64 , industrial gas price is $2.75 Y / \mathrm{m}^{3}$, and each combustion of $1 \mathrm{~m}^{3}$ of commercial quality natural gas can produce $38 \mathrm{MJ}$ (about $10.6 \mathrm{kw} \cdot \mathrm{h}$ ) energy. The refrigeration system mainly includes: the total cooling capacity is $3.6 \mathrm{MW}$ ground source heat pump, the cooling energy efficiency ratio 4.4 , that is, the ground source heat pump consumes $1 \mathrm{kWh}$ of energy, the user can get the cooling capacity of more than $4.4 \mathrm{kWh}$, a cooling capacity of $3.2 \mathrm{MW}$ base load refrigeration unit, the energy efficiency ratio 3.3 , and the general airconditioning equipment, the energy efficiency ratio 2.8.Among them, the electrical load does not contain the electric load of the electric boiler. The initial energy state of the energy storage system is $20 \%$ of the rated capacity. Due to the limitation of space, two typical scenarios are taken as examples in this paper. The corresponding random probabilities are 0.52 and 0.48 , respectively. The cold and hot electric load and the power data of photovoltaic and wind power are shown in Table $1 \sim$ Table 2. 
Table 1. Typical scenario 1 (MW)

\begin{tabular}{|c|c|c|c|c|c|}
\hline Time & $\begin{array}{c}\text { cooling } \\
\text { load }\end{array}$ & $\begin{array}{c}\text { thermal } \\
\text { load }\end{array}$ & $\begin{array}{c}\text { electrical } \\
\text { load }\end{array}$ & $\begin{array}{c}\text { photovoltaic } \\
\text { power } \\
\text { generation }\end{array}$ & $\begin{array}{c}\text { wind } \\
\text { power } \\
\text { generation }\end{array}$ \\
\hline 1 & 9.16 & 6.24 & 24.39 & 0.00 & 17.87 \\
\hline 2 & 8.10 & 3.50 & 21.74 & 0.00 & 17.95 \\
\hline 3 & 6.02 & 8.05 & 20.11 & 0.00 & 17.40 \\
\hline 4 & 5.26 & 3.80 & 19.17 & 0.00 & 18.99 \\
\hline 5 & 5.29 & 4.22 & 18.82 & 0.00 & 17.52 \\
\hline 6 & 8.55 & 7.38 & 18.83 & 0.00 & 16.20 \\
\hline 7 & 14.89 & 6.59 & 19.12 & 0.00 & 15.17 \\
\hline 8 & 15.81 & 8.09 & 20.35 & 0.00 & 12.21 \\
\hline 9 & 15.79 & 8.35 & 22.42 & 0.00 & 12.50 \\
\hline 10 & 15.87 & 8.24 & 26.18 & 0.00 & 9.03 \\
\hline 11 & 16.12 & 8.59 & 28.36 & 0.00 & 8.99 \\
\hline 12 & 16.65 & 9.05 & 29.01 & 0.00 & 7.93 \\
\hline 13 & 16.78 & 8.79 & 28.64 & 8.45 & 8.22 \\
\hline 14 & 17.69 & 4.26 & 28.33 & 11.71 & 3.43 \\
\hline 15 & 17.55 & 4.40 & 27.98 & 12.09 & 0.72 \\
\hline 16 & 17.27 & 4.61 & 27.93 & 10.95 & 0.17 \\
\hline 17 & 16.94 & 4.53 & 28.22 & 3.45 & 0.16 \\
\hline 18 & 16.52 & 4.61 & 29.11 & 2.44 & 0.12 \\
\hline 19 & 16.05 & 4.57 & 30.61 & 0.25 & 0.08 \\
\hline 20 & 15.61 & 5.06 & 35.60 & 0.00 & 0.06 \\
\hline 21 & 14.65 & 3.94 & 36.42 & 0.00 & 0.14 \\
\hline 22 & 12.56 & 5.73 & 35.23 & 0.00 & 0.19 \\
\hline 23 & 11.51 & 5.25 & 31.68 & 0.00 & 0.12 \\
\hline 24 & 10.47 & 5.90 & 27.52 & 0.00 & 0.08 \\
\hline
\end{tabular}

Table 2. Typical scenario 2 (MW)

\begin{tabular}{|c|c|c|c|c|c|}
\hline Time & $\begin{array}{c}\text { cooling } \\
\text { load }\end{array}$ & $\begin{array}{c}\text { thermal } \\
\text { load }\end{array}$ & $\begin{array}{c}\text { electrical } \\
\text { load }\end{array}$ & $\begin{array}{c}\text { photovoltaic } \\
\text { power } \\
\text { generation }\end{array}$ & $\begin{array}{c}\text { wind } \\
\text { power } \\
\text { generation }\end{array}$ \\
\hline 1 & 6.21 & 6.69 & 27.56 & 0.00 & 7.39 \\
\hline 2 & 6.10 & 3.85 & 24.75 & 0.00 & 13.13 \\
\hline 3 & 6.07 & 8.83 & 22.97 & 0.00 & 10.68 \\
\hline 4 & 6.13 & 4.13 & 22.12 & 0.00 & 10.50 \\
\hline 5 & 6.02 & 4.05 & 21.69 & 0.00 & 10.62 \\
\hline 6 & 12.30 & 7.69 & 21.98 & 0.00 & 10.74 \\
\hline 7 & 17.83 & 7.18 & 22.71 & 0.00 & 13.42 \\
\hline 8 & 18.30 & 8.46 & 25.03 & 0.32 & 14.09 \\
\hline 9 & 18.39 & 9.15 & 28.99 & 7.49 & 11.65 \\
\hline 10 & 18.76 & 7.84 & 31.30 & 13.07 & 14.07 \\
\hline 11 & 19.00 & 8.81 & 32.22 & 16.46 & 16.93 \\
\hline 12 & 19.83 & 9.21 & 31.62 & 18.76 & 16.48 \\
\hline 13 & 20.46 & 9.73 & 29.96 & 19.16 & 17.11 \\
\hline 14 & 20.38 & 3.76 & 28.02 & 18.01 & 15.69 \\
\hline 15 & 20.62 & 3.91 & 26.79 & 17.34 & 8.24 \\
\hline 16 & 20.46 & 4.15 & 26.26 & 15.27 & 5.05 \\
\hline 17 & 19.83 & 4.06 & 26.36 & 12.18 & 4.45 \\
\hline 18 & 19.61 & 4.15 & 27.32 & 6.41 & 6.96 \\
\hline
\end{tabular}

\begin{tabular}{|l|l|l|l|l|l|}
\hline 19 & 18.76 & 5.93 & 28.74 & 0.89 & 7.69 \\
\hline 20 & 18.55 & 5.60 & 32.03 & 0.00 & 8.20 \\
\hline 21 & 17.39 & 6.07 & 37.52 & 0.00 & 13.70 \\
\hline 22 & 14.85 & 8.20 & 39.71 & 0.00 & 15.79 \\
\hline 23 & 13.62 & 5.64 & 37.21 & 0.00 & 15.83 \\
\hline 24 & 12.42 & 5.39 & 32.35 & 0.00 & 18.70 \\
\hline
\end{tabular}

The purchase and sale price of the external public grid adopts time-of-use price to give full play to the leverage role of price and mobilize users to consciously adjust production plans and participate in peak and valley cutting, balanced energy use and other demand-side responses, as shown in table 3.

Table 3. Price of electricity purchased and sold online at time sharing ( $¥ / \mathrm{kWh})$

\begin{tabular}{|c|c|c|}
\hline Time & $\begin{array}{c}\text { Online electricity } \\
\text { prices on } \\
\text { timeshare } \\
\end{array}$ & $\begin{array}{l}\text { Time share online } \\
\text { electricity prices }\end{array}$ \\
\hline 1 & 0.47 & 0.3 \\
\hline 2 & 0.47 & 0.3 \\
\hline 3 & 0.47 & 0.3 \\
\hline 4 & 0.47 & 0.3 \\
\hline 5 & 0.47 & 0.3 \\
\hline 6 & 0.47 & 0.3 \\
\hline 7 & 0.47 & 0.3 \\
\hline 8 & 0.47 & 0.3 \\
\hline 9 & 0.73 & 0.52 \\
\hline 10 & 0.73 & 0.52 \\
\hline 11 & 0.73 & 0.52 \\
\hline 12 & 0.73 & 0.52 \\
\hline 13 & 0.73 & 0.52 \\
\hline 14 & 0.73 & 0.52 \\
\hline 15 & 0.73 & 0.52 \\
\hline 16 & 0.73 & 0.52 \\
\hline 17 & 0.73 & 0.52 \\
\hline 18 & 0.73 & 0.52 \\
\hline 19 & 0.73 & 0.52 \\
\hline 20 & 0.73 & 0.52 \\
\hline 21 & 0.73 & 0.52 \\
\hline 22 & 0.47 & 0.3 \\
\hline 23 & 0.47 & 0.3 \\
\hline 24 & 0.47 & 0.3 \\
\hline
\end{tabular}

Based on the model algorithm in $2.1 \sim 2.3$, the regional integrated energy system production decision scheme considering the randomness of typical scenes is shown in Fig. $2 \sim$ Fig.4. Of which, energy supplied by photovoltaic(PV) power generation is 95.43 MWh; Energy supplied by wind power(WG) is $234.14 \mathrm{MWh}$; Energy supplied by the external network(EN) is 321.79 MWh; The Combined heat and power (CHP) system's electrical generation is $91.58 \mathrm{MWh}$, and the heat generation is $143.10 \mathrm{MWh}$. The energy output of electric heating boiler(EHB) is $3.24 \mathrm{MWh}$; Refrigerating output of ground source heat pump(GSHP) refrigeration system is $317.77 \mathrm{MWh}$; Refrigerating output of base load 
refrigerating unites(BLRU) $8.4 \mathrm{MWh}$. The expected energy consumption cost of the system is 289,900 yuan.

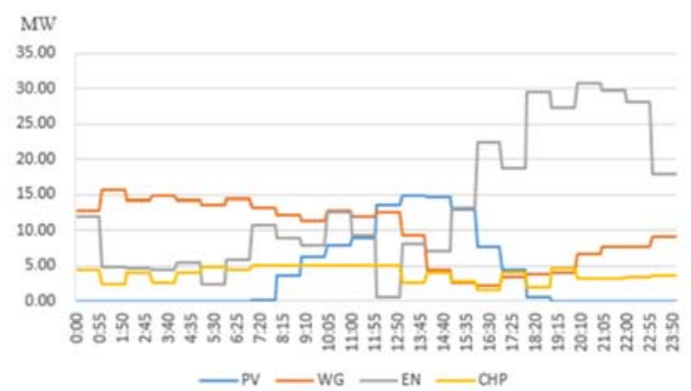

Figure 2. Output plan of electrical sources

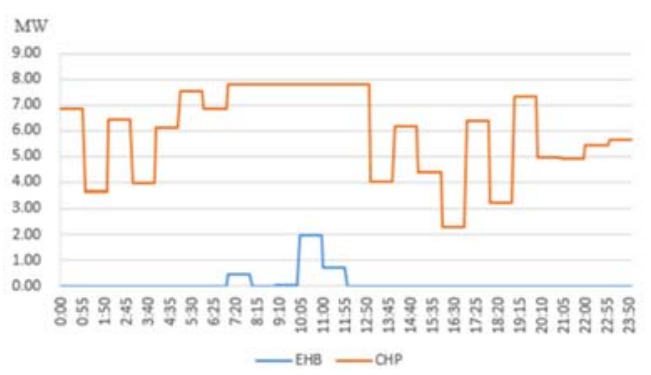

Figure 3. Output plan of heating sources

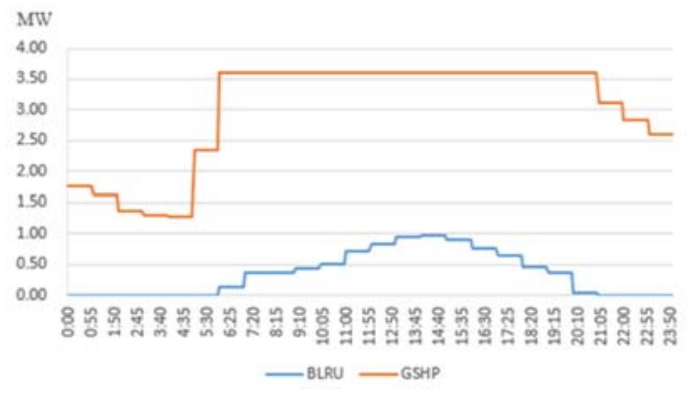

Figure 4. Output plan of cooling sources

\section{Conclusion}

The construction of a comprehensive energy system characterized by "multi-energy complementation and cooperative operation" is conducive to the improvement of energy development and utilization efficiency. At the same time, wind power, photovoltaic and other intermittent renewable energy. It makes the planning and operation of the integrated energy system uncertain. In this paper, a production simulation method of integrated energy system considering the randomness of the scene is proposed. This method firstly establishes the typical scenario set of the integrated energy system operation with the corresponding random probability through cluster analysis. Secondly, taking the regional integrated energy system as the object, a production decisionmaking model and algorithm aiming at minimizing the expected cost of energy consumption are proposed. Finally, the effectiveness of the model algorithm is verified by a case study. The stochastic production simulation method applicable to the reliability assessment of integrated energy systems will be further studied in the future to support the planning and scheduling decisions of integrated energy systems.

\section{Acknowledgments}

This work is supported by science and technology project of state grid corporation of China: "Research on dispatch and control technology of urban integrated energy system in Xiongan new area”（No. SGHE0000DKJS1900094）.

\section{References}

1. WANG Xifan. EEF approach to power system probabilistic modeling[J]. Journal of Xi'an Jiaotong University, 1984, 18(6):13-26.(in Chinese).

2. YAN Mao-song, ZOU Bin. The cumulant method using available capacity distribution based on chronological load curve for production simulation of power system [J]. Control and Decision 1992 7(1): 41-47(in Chinese).

3. XIA Qing, Wang Shaojun, Xiang Niande. The probabilistic power system production simulation based on chronological load curve [J]. Proceedings of the CSEE, 1994, 14(3): 21-28(in Chinese).

4. KANG Chong-qing, XIA Qing, XIANG Nian-de, et al. Sequence operation theory and its applications[J]. Automation of Electric Power Systems, 2002, 26(17): 6-11(in Chinese).

5. QIU Yanhui, CHEN Daolian, JIANG Jiahui. Circuit Structure and Energy Management Control Strategy of Multi-energy Joint-power-supply System[J]. Power Electronics,2017,51(3): 43-47.

6. PENG Yuanxiu, YANG Yihua, QIU Xiong, et al. Research on Microgrid Cluster Scheduling Based on Rolling ADMM [J]. Power Electronics,2018,52(10): 38-41.

7. HUANG Zonghong, CAO Yuchen, HU Zhibing, et al. Energy Management of Industrial Park Integrated Energy System Based on Improved Genetic Algorithm [J]. Electric Power Construction,2019,40(8): 51-58.

8. WU Jiahao, ZEN Cehengbi, MIAO Hong. T Coordinated Ecnomic Scheduling for Multi-Regional Integrated Energy System Considering Energy Exchange Between Sub-Regions [J]. Electric Power Construction,2019,40(11): 39-47. 